\title{
Effects of different sleeping patterns on academic performance in medical school students
}

\author{
Aabid Ali $^{1}$, Muhammad Bilal Majeed ${ }^{1}$, Kanwal Saba $^{2}$, Amanda Bodenarain $^{3}$, \\ Mulazim Hussain Bukhari ${ }^{3 \#}$ \\ ${ }^{1}$ King Edward Medical University, Lahore, Pakistan \\ ${ }^{2}$ Department of Pathology, Demonstrator, King Edward Medical University, Lahore, Pakistan \\ ${ }^{3}$ American University of Barbados, School of Medicine Barbados, St. Michael, Barbados; \\ \#Corresponding Author: mulazim.hussain@gmail.com, www.aubmed.org
}

Received 16 July 2013; revised 16 August 2013; accepted 25 August 2013

Copyright (C 2013 Aabid Ali et al. This is an open access article distributed under the Creative Commons Attribution License, which permits unrestricted use, distribution, and reproduction in any medium, provided the original work is properly cited.

\section{ABSTRACT}

In the past, efforts have been made to determine the influence of sleep quantity and its deprivation, on functioning efficiency of human beings. However, determination of sleeping patterns that could improve intellectual performance has been largely neglected. This study is designed to discover the effects of different sleeping patterns on academic performance among medical students. A descriptive study was carried out in King Edward Medical University in Lahore, Pakistan during a six-month time span from May $11^{\text {th }}, 2011$ to September $30^{\text {th }}, 2011$. Of the total population of 1350 students in King Edward Medical University, 591 undergraduates were included in the study. A questionnaire designed on sleeping patterns and academic performance was distributed in May 2011. What was described as outstanding students were greater in number in group 4 (7/19) 36.8\% and group 6 (6/19) 31.6\%. Above average students with sleeping patterns were in group 4 (13/37) 35.1\% and group $6(10 / 37)$ 27\%. Average students were shown to have sleeping patterns of group 4 (11/25) $44 \%$ and group 6 (7/25) 28\%. Below average students were shown to have sleeping patterns of group $4(3 / 3) 100 \%$. Most of our students had a reduction in the total amount of sleeping hours throughout the years. Midnight to 6 o'clock in the morning with an afternoon nap was the sleeping pattern that was most commonly seen in all groups. We concluded that different sleeping patterns do not affect the

\footnotetext{
*Conflict of interest: The authors report no conflict of interest in this
} work. performance of medical students in the academic prospective. Many other factors may be involved in the lack of significant achievement, in order to prove that the sleeping patterns are not related to the academic performance, and more data would need to be collected.

Keywords: Medical Student; Sleeping Patterns; Academic Performance

\section{INTRODUCTION}

Sleep plays a fundamental role in the lives of human beings, which is thought to affect the competence of their customary activities. Human beings, like other species, frame their routine according to a 24-hour cycle, and this organization depends upon endogenous and environmental factors. The pattern of sleep and wakefulness in different subjects is known to vary with their age, the demands of their occupation, their physiological and psychosocial characteristics, psychiatric illness and some type of physical illness [1].

The sleep wake cycle is a circadian rhythm which is spontaneously generated by the organism with a periodicity, in the adult, of about one day [2]). Therefore we tend to maintain relatively stable schedules. Since the sleep wake cycle is in harmony with other circadian rhythms such as, deep body temperature and cellular mitosis, abrupt shift of sleep schedules can lead to internal dissociation among circadian rhythms which may imply undesirable effects such as somnolence, attention deficits and performance decrements which are very common in working shifts and rapid travel across multiple time zones [3].

Most sleep specialists agree that, although adults require 8 hours of sleep per day, sleep patterns of young 
adults differ from those of their adult counterparts in several ways, including a need for increased sleep [4].

However, some people need more than 9 hours of sleep (long sleepers) while others feel well with less than 6 hours of sleep (short sleepers). Adolescents undergo a phase delay in sleep onset accompanied by increased irregularities in their sleep patterns, jeopardizing sleep sufficiency in students [5]. Phase delay coincides with the pubertal onset, but the tendency to sleep late goes well into the twenties [6]. According to the International Classification of Sleep Disorders, conditions such as dyssomnias, parasomnias and medical/psychological disorders which are often neglected, may be responsible for altered patterns among students and as a result students may use drugs to overcome these problems [7-8].

There are other individual variations as well. On one hand, there is the morning type of people who tend to be drowsy during the evening and enjoy going to bed and waking up early. These morning people perform much better in the morning (work, mood) and become increasingly tired throughout the day. On the other hand, evening type people like to go to bed and wake up late, when possible. They do not perform well in the morning, become increasingly alert throughout the day and feel their best in the afternoon and evening. They have a much higher tolerance to evening work than most people. However, the majority of people are of the intermediate type [3].

Sleep is clearly an important aspect of successful academic and personal life in college, yet very little attention has been given to finding an appropriate sleeping pattern. This study was designed to discover a relationship between a healthy sleeping schedule and academic success in the undergraduates of King Edward Medical University, Lahore so that we may be able to encourage medical students to seek healthier sleep habits, by using academic success as motivation. Students mindful of the importance of healthy sleep patterns may be able to improve their achievements.

\section{MATERIALS AND METHOD}

The study was carried out in King Edward Medical University, Lahore from May $11^{\text {th }}, 2011$ to September $30^{\text {th }}$, 2011. Out of 1350 students, 591 students (379 female and 212 male) consented to participate. All students selected were aged between 18 to 23 years. Academic performance was analyzed on the basis of percentage marks in previous professional examinations. First year students were excluded, as they have not taken any professional examinations yet. The data of the 591 students were arranged in a list according to their registration numbers. Then a probability sampling technique was used in which randomly, every $7^{\text {th }}$ student was selected for analysis, reducing the sample size to 84 (55 female and 29 male). The study design was descriptive.

For convenience, we divided students into six groups on the basis of sleeping patterns.

1) GROUP 1 (sleep from $10.00 \mathrm{PM}$ to $6.00 \mathrm{AM}$ ),

2) GROUP 2 (sleep from $10.00 \mathrm{PM}$ to $6.00 \mathrm{AM}$ and take an afternoon nap),

3) GROUP 3 (sleep from 12.00 Midnight to $6.00 \mathrm{AM}$ ),

4) GROUP 4 (sleep from 12.00 Midnight to $6.00 \mathrm{AM}$ and take an afternoon nap),

5) GROUP 5 (after 12.00 Midnight to late in the morning),

6) GROUP 6 (after 12.00 Midnight to late in the morning and take an afternoon nap). On the basis of academic performance in respective professional examinations, we divided students into four groups.

a) Outstanding students (score above $70 \%$ ),

b) Above average students (score 65\% - 70\%),

c) Average students (score 60\% - 65\%),

d) Below average students (score $50 \%$ - 60\%).

Data collection was done by a specially designed questionnaire, which was comprised of questions regarding routine sleeping schedule and academic performance over the past year. The six most common sleeping patterns were included in our questionnaire, which were designed on the basis of observation of routine sleeping habits of medical students in King Edward Medical University, Lahore. In addition, they were also asked about their morning lecture attendance, understandings of lectures, extracurricular activities, sleep habits on weekends and other questions pertaining to their normal routine. The observational protocol was approved by the Institutional Review Committee of King Edward Medical University. All data were entered on Performa and analyzed using SPSS version 17.

\section{RESULTS}

Two types of sleeping patterns were predominately seen in outstanding students (7/19) 36.8\%; sleeping pattern of group 4, sleep from 12.00 midnight to 6.00 AM with afternoon nap, and secondly (6/19) 31.6\%; sleeping pattern of group 6, sleep after 12.00 midnight to late morning with afternoon nap (Figure 1, Tables 1 and 2).

Above average students had a predominant sleeping pattern of group 4, with sleep from midnight 12.00 to 6 AM and afternoon nap (13/37) 35.1\% and group 6 (10/37) 27\% (Figure 2, Tables 1 and 2).

Average students with sleeping pattern of group 4 (11/25) 44\% and group 6 (7/25) 28\% with the sleeping pattern of after 12.00 Midnight to late morning and nap in the afternoon (Figure 3, Tables 1 and 2).

Below average students with sleeping pattern of group 4 (3/3) 100\% (Figure 4, Tables 1 and 2).

The sleeping pattern was not significantly different in all four groups of the students $(\mathrm{P}=0.758)$, which is less 
Table 1. Relationship between academic performance and sleeping pattern.

\begin{tabular}{cccccc}
\hline \multirow{2}{*}{$\begin{array}{c}\text { No. of } \\
\text { group }\end{array}$} & \multicolumn{4}{c}{ Percentage marks in previous examination } & \\
\cline { 2 - 5 } & Above 70\% & $65 \%-70 \%$ & $60 \%-65 \%$ & $50 \%-60 \%$ & \\
\hline Group 1 & $10.5 \%$ & $10.8 \%$ & $4 \%$ & $0 \%$ & $8.3 \%$ \\
Group 2 & $5.3 \%$ & $8.1 \%$ & $8 \%$ & $0 \%$ & $7.1 \%$ \\
Group 3 & $5.3 \%$ & $16.2 \%$ & $16 \%$ & $0 \%$ & $13.1 \%$ \\
Group 4 & $36.8 \%$ & $35.1 \%$ & $44 \%$ & $100 \%$ & $40.5 \%$ \\
Group 5 & $10.5 \%$ & $2.7 \%$ & $0 \%$ & $0 \%$ & $3.6 \%$ \\
Group 6 & $31.6 \%$ & $27 \%$ & $28 \%$ & $0 \%$ & $27.4 \%$ \\
\hline
\end{tabular}

Table 2. Types of sleeping patterns were predominately seen in students.

\begin{tabular}{cccc}
\hline Students categories & Sleeping pattern & Numbers & Percentage \\
\hline \multirow{2}{*}{ outstanding students } & Group 4 & $7 / 19$ & $36.8 \%$ \\
& Group 6 & $6 / 19$ & $31.6 \%$ \\
Above average students & Group 4 & $13 / 37$ & $35.1 \%$ \\
& Group 6 & $10 / 37$ & $27 \%$ \\
Average students & Group 4 & $11 / 25$ & $44 \%$ \\
Below average students & Group 6 & $7 / 25$ & $28 \%$ \\
\hline
\end{tabular}

\section{Outstanding students}

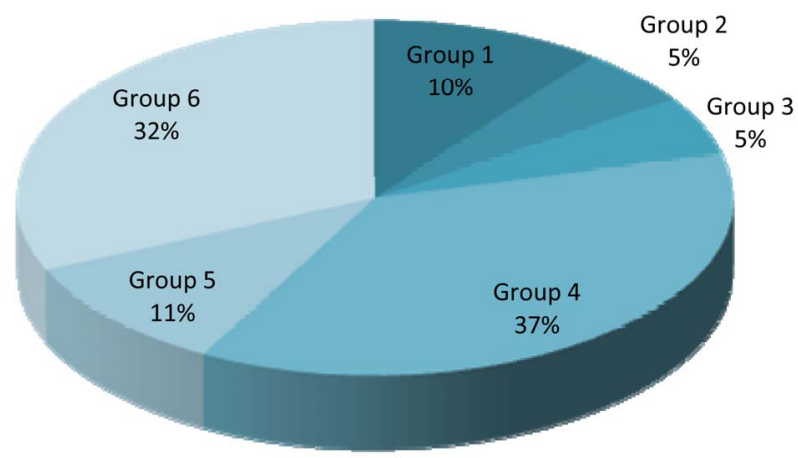

Figure 1. Showing distribution of outstanding students in various groups.

than the value of significance.

\section{DISCUSSION}

The study was conducted to evaluate the effects of sleeping patterns on the academic performance of medical students at King Edward Medical University, Lahore. However, results do not confirm the hypothesis that any particular pattern effects academic performance of

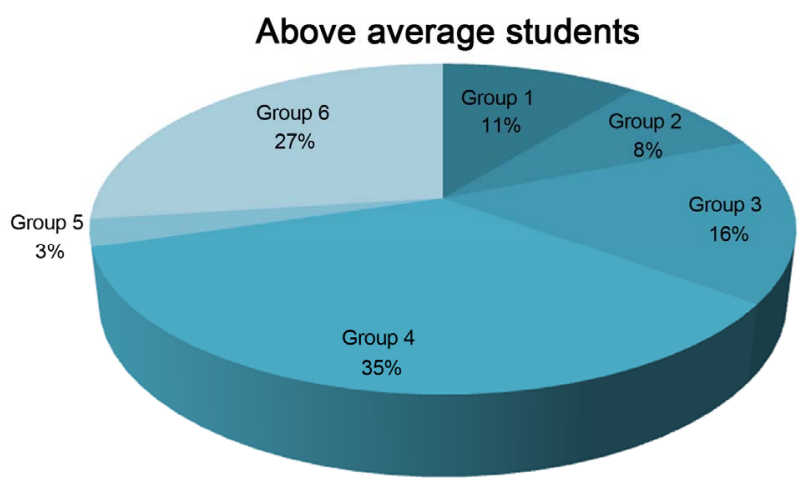

Figure 2. Pattern showing distribution of above average students in various groups.

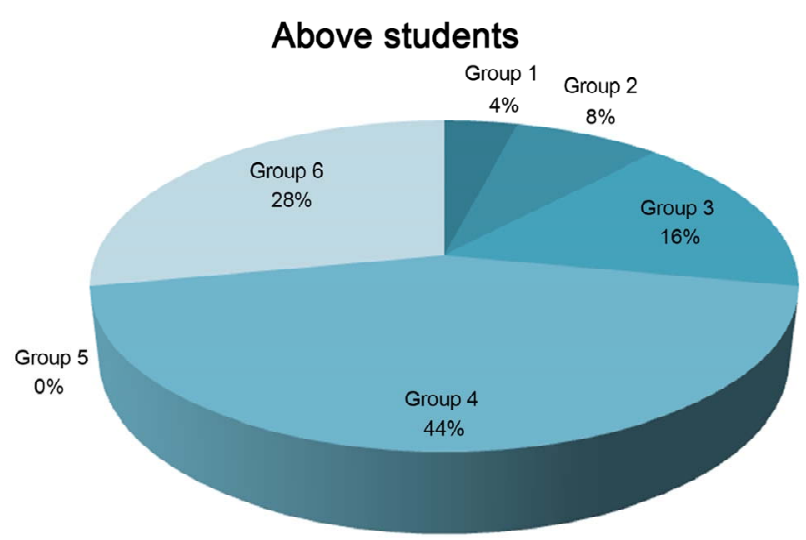

Figure 3. Pattern showing distribution of average students in various groups.

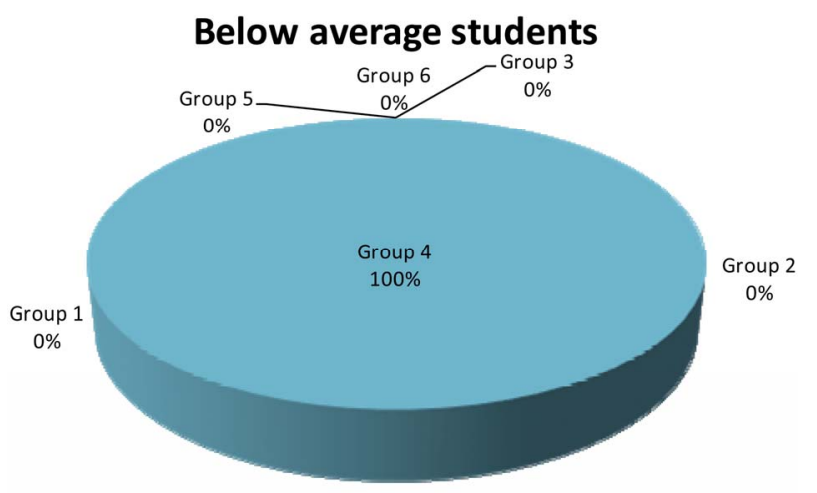

Figure 4. Pattern showing distribution of below average students in various groups.

medical students. There is no significance among our two variables: sleeping pattern and academic performance, therefore we cannot predict with confidence that student's grades would be improved by adapting a particular sleeping pattern, although the possibility is not excluded.

Our study showed that outstanding students were those who slept for more than 6 hours like in the group 4 sleep pattern (sleep from 12.00 Midnight to 6.00 AM and take 
an afternoon nap) or group 6 sleep pattern (sleep after 12.00 Midnight to late in the morning and take an afternoon nap) but the majority of students who usually were below average, were also mostly in the category with less sleep. However, there were students with average or below average progress that also had a sleeping pattern of group 4. The findings are consistent with the reports mentioned in world literature.

As sleeping pattern is not related to academic performance, we can explore other aspects in the routine of students that may have an effect, like eating habits, exercise, mood and perceived stress [9]. Poorer academic performance was related significantly to reduction in night time sleep [10] and later times of waking up in the morning [11], however no such association was found in our research. Socioeconomic status also effects sleep and academic performance [12]. Sleep deprivation can cause attention deficits, daytime somnolence, and depressive mood with impaired daytime performance. Most effective counter measure of sleepiness is sleep [13-15].

Medical students are subjected to high levels of stress during their academic year that can lead to psychological problems resulting in sleep disturbances. They have day and night time ward rounds, seminars, presentations, weekly and monthly assessment tests and other extracurricular activities, which they have to complete in a limited period of time. These activities increase the incidence that their actual bedtime will be pushed back. Moreover, students come from different backgrounds in different areas, they have different styles of studying, and different capabilities to cope with routine pressures resulting in different sleeping patterns. Therefore, students having difficulties in their academics should be screened for sleep insufficiency [16-18].

Academic achievements may depend on additional factors. Factor analysis of sleep habits in several groups of subjects have shown that sleep may vary in its characteristics, along with several independent dimensions simultaneously in addition to its quantity [19]. Thus, failure to demonstrate a relationship between academic performance and amount of sleep obtained is not surprising. Previously it was demonstrated that although some sort of sleep difficulty affected a large number of students as well, its full impact on academic performance has remained unknown. Behavioral interventions, often recommended as important sleep aid, include exercise and alleviating stress and worries have shown promising results $[20,21]$.

Due to the various responsibilities students possess, they cannot go to bed earlier and as a result may obtain insufficient sleep to perform well next day. In a study by Lowry M., sleep deprived students also scored high as they engaged themselves in more positive activities in place of sleep, like studying. This is in accordance with our findings as students who scored higher in profes- sional examinations, were most commonly involved in studying whenever they were up late at night. Meanwhile below average students were mostly busy with extracurricular activities like gossiping, roaming and smoking. Thus, a more dedicated attitude toward studying seems to be significant, rather than the amount of time a student spends sleeping. Prolonged low quality sleep may result in the student's inability to cope with academic demands. This was the same case with below average students who reported that their sleep was mostly interrupted by a variety of factors. In most of these cases, waking up from sleep is unpleasant as most students reported developing a headache and finding it difficult to go back to sleep afterwards which may lead to inadequate sleep [22-24].

Several limitations that may have affected our result are as follows: students themselves gave the data and they may not have reported their sleeping habits accurately. In addition, the sleeping pattern design was based on the six most common sleep habits in undergraduates of our university, so generalization may be difficult. Next, the sleep pattern questionnaire has not been formally validated. Sleep pattern differences due to general and cultural variation may have affected the results as well. Our study shows that brain functioning is not affected by adopting any standard sleeping pattern, as there are variations among individuals according to which they frame their daily activities. Irregularities in the sleep schedule do have an impact on the capabilities of students, as their circadian rhythm is affected leading to decreased attention span. Similarly, practical efforts to outshine in annuals also play an important role in success in academic career. Quantity of sleep matters in curricular activities, but sleeping pattern may not have any significant affect on educational routine. Lack of interest in studies, wastage of time in extra-curricular activities, frequent sleep interruptions throughout the night, hostel related issues are some other factors that can affect academic performance.

\section{CONCLUSION}

We found that most of the students had reduced sleeping hours over the course of the year. Midnight to 6 o'clock in morning with an afternoon nap sleeping pattern was most commonly seen in all groups. We concluded that different sleeping patterns do not affect performance of medical students in the academic prospective. Many other factors may be involved in the lack of significant achievement, in order to support that the sleeping patterns are not related to academic performance; more data would be needed.

\section{RECOMMENDATIONS}

1) Further studies are recommended to find out any rela- 
tionships between the two entities, in order to prove that the sleeping patterns are not related to the academic performance, in which more data would be needed.

2) A global survey should be done to analyze different sleeping patterns so that further work can be done on this topic.

3) Instead of looking for suitable sleeping patterns, students should make a balanced schedule involving sufficient sleep.

4) A receptive mind in class as well as more concentration toward lectures can increase academic performance.

5) The use of drugs in order to stay up late before examinations or in any other circumstance can affect the student's performance adversely.

6) We highly recommend hostel management to pay extra attention toward major and minor issues of students so that their attention in classes can be improved.

7) Students should study without any other thoughts and with full concentration.

8) The circadian rhythm can be balanced with a moderate sleeping schedule and regular wakeup times, increasing the outcome of the student's efforts.

\section{AUTHOR'S CONTRIBUTION}

Aabid Ali: (Medical Student; aabidalidr@gmail.com) King Edward Medical University, Lahore, designed questionnaire, collected, analyzed and compiled the results, drafted the manuscripts.

Muhammad Bilal Majeed (Medical Student; bilalmajeed.1990@gmail.com) designed questionnaire, collected, analyzed and compiled the results, drafted the manuscripts.

Kanwal Saba: (MBBS, MSc, MPhil; kanwalsaba144@gmail.com) Department of Pathology, King Edward Medical University assisted throughout drafting the manuscript/

Amanda Bodenarain (MD-4 Student; abodenarain@gmail.com) American University of Barbados, School of Medicine, www.aubmed.org; made editing, reanalyzed the data.

Mulazim Hussain Bukhari (MBBS, DCP, MPhil, FCPS, PhD), Prof of Pathology and Associate Dean, American University of Barbados, School of Medicine. www.aubmed.org (18-Wildey Estate, St. Michael, Barbados; 14007BB Ex-Chairman DPCC and Director PhD Program. King Edward Medical University Lahore: Pakistan, supervised the research (Corresponding Author).

\section{ACKNOWLEDMENTS}

We are deeply indebted to the Department of Pathology, Department of Physiology and Department of Pharmacology for their consent to distribute the questionnaire during their lectures.

\section{REFERENCES}

[1] Masterton, J.P. (1965) Sleep of hospital medical staff. Lancet, 1, 41-42.

[2] Minors, D.S. and Waterhouse, J.M. (1981) Endogenous and exogenous components of circadian rhythms when living on a 21-hour day. International Journal of Chronobiology, 8, 31-48.

[3] Gomes, A.A., Azevedo, M.H. and Tavares, J. (2002) Sleep-wake patterns and academic performance in university students.

[4] Gray, E.K. and Watson, D. (2002) General and specific traits of personality and their relation to sleep and academic performance. Journal Personality, 70, 177-206.

[5] Roenneberg, T., Kuehnle, T., Pramstaller, P.P., Ricken, J., Havel, M., Guth, A., et al. (2004) A marker for the end of adolescence. Current Biology, 14, R1038-1039.

[6] Wolfson, A.R. and Carskadon, M.A. (1998) Sleep schedules and daytime functioning in adolescents. Child Development, 69, 875-887.

[7] Gaultney, J.F. (2011) The prevalence of sleep disorders in college students: Impact on academic performance. The Journal of American College Health, 59, 91-97.

[8] Shafiq, M., Shah, Z., Saleem, A., Siddiqi, M.T., Shaikh, K.S., Salahuddin, F.F., Siwani, R. and Naqvi, H. (2006) Perceptions of Pakistani medical students about drugs and alcohol: A questionnaire-based survey. Substance Abuse Treatment, Prevention, and Policy, 1, 31.

[9] Wolfson, A.R. and Carskadon, M.A. (2003) Understanding adolescent's sleep patterns and school performance: A critical appraisal. Sleep Medicine Reviews, 7, 491-506. http://dx.doi.org/10.1016/S1087-0792(03)90003-7

[10] Perez-Chada, D., Perez-Lloret, S., Videla, A.J., Cardinali, D., Bergna, M.A., Fernández-Acquier, M., et al. (2007) Sleep disordered breathing and daytime sleepiness are associated with poor academic performance in teenagers. A study using the Pediatric Daytime Sleepiness Scale (PDSS). Sleep, 30, 1698.

[11] Johns, M.W., Dudley, H.A. and Masterton, J.P. (1976) The sleep habits, personality and academic performance of medical students. Medical Education, 10, 158-162.

[12] Denver, C. (2007) Adolescent sleep disturbance and school performance: The confounding variable of socioeconomics. Journal of Clinical Sleep Medicine, 3, 19.

[13] Czeisler, C.A. (2009) Medical and genetic differences in the adverse impact of sleep loss on performance: ethical considerations for the medical profession. Transactions of the American Clinical and Climatological Association, 120, 249.

[14] Eliasson, A., King, J. and Gould, B. (2002) Association of sleep and academic performance. Sleep and Breathing, 6, 45-48. http://dx.doi.org/10.1055/s-2002-23157

[15] Veasey, S., Rosen, R., Barzansky, B., Rosen, I. and Owens, J. (2002) Sleep loss and fatigue in residency 
training. JAMA: The Journal of the American Medical Association, 288, 1116-1124.

http://dx.doi.org/10.1001/jama.288.9.1116

[16] Lima, P., Medeiros, A. and Araujo, J. (2002) Sleep-wake pattern of medical students: early versus late class starting time. Brazilian Journal of Medical and Biological Research, 35, 1373-1377. http://dx.doi.org/10.1590/S0100-879X2002001100016

[17] Sherina, M., Rampal, L. and Kaneson, N. (2004) Psychological stress among undergraduate medical students. Medical Journal of Malaysia, 59, 207-211.

[18] Fallone, G., Acebo, C., Seifer, R. and Carskadon, M.A. (2005) Experimental restriction of sleep opportunity in children: effects on teacher ratings. Sleep-New York Then Westchester, 28, 1561.

[19] Johns, M.W. (1975) Factor analysis of subjectively reported sleep habits, and the nature of insomnia. Psychological Medicine, 5, 83-88.

[20] Buboltz, W.C., Jr., Brown, F. and Soper, B. (2001) Sleep habits and patterns of college students: A preliminary study. The Journal of American College Health, 50, 131135.

[21] Caldwell, K., Harrison, M., Adams, M., Quin, R.H. and Greeson, J. (2010) Developing mindfulness in college students through movement-based courses: Effects on self-regulatory self-efficacy, mood, stress, and sleep quality. Journal of American College Health, 58, 433-442. http://dx.doi.org/10.1080/07448480903540481

[22] Thomas, C.B. and Pederson, L.A. (1963) Psychobiological studies. II. Sleep habits of healthy young adults with observations on levels of cholesterol and circulating eosinophils. Journal of Chronic Diseases, 16, 1099-1114.

[23] Lowry, M., Dean, K. and Manders, K. (2010) The link between sleep quantity and academic performance for the college student.

[24] Johns, M.W., Bruce, D.W. and Masterton, J.P. (1974) Psychological correlates of sleep habits reported by healthy young adults. British Journal of Medical Psychology, 47, 181-187. 